\title{
A large-scale study on the speed-calming effect of speed humps
}

\author{
Niels Agerholm ${ }^{a}$, Lasse Høyrup Sørensen ${ }^{b}$, Pelle Rosenbeck Gøeg ${ }^{a}$, \\ Harry Lahrmann ${ }^{a}$, Anne Vingaard Olesen ${ }^{a}$ \\ ${ }^{a}$ Department of the Built Environment, Aalborg University, Thomas Manns Vej 23, Aalborg Oe, 9220, Denmark \\ ${ }^{b}$ COWI Aalborg, Visionsvej 53, 9000 Aalborg, Denmark
}

ABSTRACT: Inappropriate speeding is one of the main causes for traffic-related injuries and fatalities. Studies have shown that more than $50 \%$ of Danish car drivers regularly speed on urban roads and nearly $75 \%$ of them speed on rural roads. Physical speedcalming measures, particularly speed humps, are widely used to reduce speeding in urban areas in the Danish road network. However, speed humps are often located based on reasons other than ensuring that they have the best effect on reducing the speed of vehicles. Furthermore, their speed-calming effect is not utilised sufficiently. This study evaluated more than 570 speed humps on roads with a $50 \mathrm{~km} / \mathrm{h}$ speed limit. The main results reveal that speed increases with an interval between speed humps of up to $200 \mathrm{~m}$ at approximately $60 \mathrm{~km} / \mathrm{h}$. Additionally, a positive correlation was found between the distance from the roadside to the roadside buildings. The actual interval between speed humps ensures that suitable driving behaviour is carried out is $52 \mathrm{~m}, 70 \mathrm{~m}$ and $164 \mathrm{~m}$ for through roads, main roads and residential roads, respectively, in cases in which roadside buildings are situated farther from the road. Similar values were found for the intervals between speed bumps on these three types of roads (67 m, $89 \mathrm{~m}$ and $261 \mathrm{~m}$, respectively) when there is a shorter distance between the roadside and the roadside buildings. Overall, speed humps are an efficient way to reduce speeding in built-up areas; however, aside from the interval between the speed humps, the distance from the roadside to the roadside building is the only significant factor contributing to the speed of the car for drivers on these roads.

KEYWORDS: Speed Calming; Speed Humps; Traffic Safety

\section{BACKGROUND}

Inappropriate speeding is a key factor that contributes to the increased risk of accidents, injuries and fatalities in a road network (Nilsson, 2004; Elvik, 2013). Additionally, speeding has a negative effect on security (Hauer, 1997). Even minor speed offences are known to increase the risk markedly, especially for unprotected road users (Rosén, Stigson \& Sander, 2011; Elvik, 2013). This increases the importance of reducing speeding problems on roads in built-up areas, as the drivers often operate their vehicles at higher speeds than what is recommended (Karlgren, 2005; Eksler, Popolizio, \& Allsop, 2009; Rosén, Stigson, \& Sander, 2011; Antic, Pesic, Vujanic, \& Lipovac, 2013). For decades, it has been clear that neither information nor police enforcement can sufficiently reduce the problem of speeding (Agerholm, 2011). Therefore, to avoid speeding in urban areas, physical speed calming (SC) measures are required where the road design does not hinder speeding (Várhelyi, 1996).

A range of SC measures has been used in different variations in various countries, and their positive effect on traffic safety has been proven (Elvik, 2001; Wellis et al., 2004; Elvik et al., 2009). However, the presentation of the different solutions is based on those used in the Danish road network as they are suggested to include most types of SC physical measures, especially those that are relevant to this study. In general, physical SC measures can be speed humps, speed bumps, narrowing and elevated surfaces (Danish Road Directorate, 2013). In this paper, speed humps refer to rather long elevated areas with a length (measured in longitudinal direction to the road) of 8-10 m of a road with a soft shift to the road surface. Speed bumps are understood as short (in longitudinal direction) elevated units that, in general, 
reduce the speed of a vehicle to very low levels, with subsequent accelerations. This study aimed to study speed humps that allow for driving at the speed limit without discomfort while also ensuring significant discomfort if the driver is speeding. A more detailed description can be found in Agerholm, Knudsen, and Variyeswaran (2017). While a range of intelligent transport systems have SC effects, they are not elaborated on in this paper.

The effects of speed humps have been studied in a range of small-scale studies. An older Danish study conducted in connection with establishing SC thoroughfares showed significant positive effects on driving behaviour (Rosbach, 1996). Additionally, 14 Swedish urban street segments were investigated to determine their speed pattern in relation to various characteristics of the segments. The mean speed on these streets was $23-49 \mathrm{~km} / \mathrm{h}$; the highest value was on a straight segment without SCs and the maximum speed was $73 \mathrm{~km} / \mathrm{h}$. These street segments were located in dense urban areas with surrounding apartment buildings and with a short visual range. This Swedish study also found that speed was reduced on roads where the roadside buildings were tall and situated close to the lane, and vice versa (Karlgren, 2005). In Serbia, a study based on the laser registration of speed found a lasting effect for speed bumps with a length of $0.96 \mathrm{~m}$ (i.e. a much shorter length in comparison to speed humps). The effect was measured only at distances of $25 \mathrm{~m}$ and $40 \mathrm{~m}$ from the SC. The effect was almost persistent over time, but the vehicle speeds increased between the speed bumps. The $85^{\text {th }}$ percentile speed (85-speed) was below the speed limit on the entire midblock after establishing the speed bumps (Antic, Pesic, Vujanic, \& Lipovac, 2013). Another Global Navigation Satellite System (GNSS)-based small-scale study on thoroughfare speed humps in five minor villages showed that speed humps should be closer than $150 \mathrm{~m}$ to each other to keep the 85 -speed below a $50 \mathrm{~km} / \mathrm{h}$ speed limit. They also found that roadside building density had an effect on the speed. Although it was not possible to estimate the direct effect of the roadside building, it appeared that the denser the street area, the lower the recognisable speed (Jørgensen et al., 2013). A more significant effect was found in a study conducted in Israel on urban arterial roads in medium-sized towns (Gitelman et al., 2016). In that study, eight raised pedestrian crossings resulted in a reduction of the mean speed and an 85 -speed of up to $29 \mathrm{~km} / \mathrm{h}$, and the effect was persistent over time (Gitelman et al., 2016).
Moreover, the establishment of sinus-shaped speed humps (height: $10 \mathrm{~cm}$; length: $950 \mathrm{~cm}$ ) and chicanes (narrowing) was studied using Floating Car Data (FCD) from 3,216 trips of vehicles passing one or more SCs. The main results were that the effect from SCs on mean speed and 85-speed decreased as the distance to/from the nearest SC increased to approximately $75 \mathrm{~m}$. When the distance to/from the SC is greater, it is difficult to identify a clear connection between the distance to/from the SC and the speed choice. This is reasonable because other factors, such as the distance from the roadside to the roadside buildings, which has a significant effect on the speed choice when the SC is more than $75 \mathrm{~m}$ away. While the use of speed humps and chicanes resulted in an almost identical speed reduction, the use of speed humps alone resulted in a greater reduction in the speed variation (Agerholm, Knudsen, \& Variyeswaran, 2017). In a test setup used to measure the SC effects from speed humps and speed cushions in Brno (CZ), Vilnius (LT) and Kraków (PL), a range of data collection methods were used to ensure that the data were obtained only under free flow conditions. The first were with a $30 \mathrm{~km} / \mathrm{h}$ speed limit while the latter were with a $50 \mathrm{~km} / \mathrm{h}$ speed limit. In total, 9 midblocks with 3-9 humps/cushions were included. The main result was that the mean zone of influence included a distance ranging between $31-75 \mathrm{~m}$ and the mean speed was reduced by $13-21 \mathrm{~km} / \mathrm{h}$ (Ambros et al., 2017).

While these studies showed that speed humps have an SC effect, the local design of the measured road midblock and the speed humps differ, and the more general effects are not clear. Therefore, there is limited documentation regarding the persistence of the effects of speed humps on minor urban streets without dense buildings and with a straight curvature. While many (mainly older) studies are based on speed measurement in spots and, hence, an unclear persistence, others have measured the effects of SC on road segments with a lower distance of visibility. Thus, this study aimed to clarify which effect the interval between the speed humps has on the speed of a road midblock with a straight shape.

\section{DATA}

Data regarding driving behaviour was extracted from the Danish research and innovation project, the ITS Platform; the data were collected from May 
2012 to December 2014. In total, 431 mainly privately-operated cars were equipped with an onboard unit that collected driving data with $1 \mathrm{~Hz}$. Data included position, speed, direction, car ID and accelerations, and were subsequently denoted as FCD (Lahrmann et al., 2012, 2013; Agerholm et al., 2014). A total of 1.3 billion FCD points, equivalent to a distance of 15 million $\mathrm{km}$ driven, were collected (Gøeg et al., n.d.). Because the ITS Platform was operated within the centre of North Denmark, the majority of the FCD were collected there, and only the FCD and data about speed humps in the North Denmark Region were included.

All the midblocks included in the study were two-lane roads in built-up areas equipped with two or more speed humps, as defined in Section 1. For each interval between the speed humps, the following data were recorded:

- Interval between speed humps (m);

- Road type: 1: local residential road, 2: main road between neighbourhoods, 3: through roads;

- Roadside characteristics: 1: bicycle path (elevated with curb), 2: pedestrian area (elevated with different surfaces and curbs), 3: bicycle lane (same level with painted delimitation) and 4: distance to buildings $(\mathrm{m})$ and road width $(\mathrm{m})$. Road width and distance to buildings were categorised in tertiles.

The distance between two speed humps was defined as an interval. The midblocks from a change in the speed limit to the nearest speed humps and vice versa were not included in order to avoid the effects from the shift in speed limits, etc. To eliminate any additional speed-effect factors, the included intervals fulfilled the following conditions:

- Located in built-up areas;

- A speed limit of $50 \mathrm{~km} / \mathrm{h}$ (the speed limit in Danish built-up areas if no further restrictions are provided);

- No bends in the road geometry that affect driving behaviour;

- No other SC measures (narrowing, chicanes, elevated surfaces, roundabouts, etc.);

- Always the priority road;

- No other identifiable speed-reducing design elements.
Data concerning the speed humps was collected via manual inspection of high-resolution orthophotos and saved in a geographical information system (GIS). They were then sorted in order to retain the data that fulfilled the requirements listed above and that were connected with the pertinent FCD. Information about road type was collected from scrutinising the midblocks, which are equipped with speed humps, on orthophotos from the Danish Map Authorities and on Google Street View in combination with the road authorities' road plans. Information about the presence of bicycle paths, bicycle lanes, pedestrian areas and road width was extracted from the Danish national road database. The distance to buildings was measured using orthophotos.

\section{METHODS}

The relevant FCD for this study were extracted from the FCD from the ITS Platform, as noted above. Only FCD that could be geographically connected to the selected midblock were extracted. The FCD were map-matched to their pertinent midblock to organise the data. This was done for all trips driven on each road interval. Then, the maximum speed for each trip at each road interval was identified. Afterwards, the maximum speeds for all trips were identified, and the $85^{\text {th }}$ percentile of all maximum speed (subsequently denoted as 85 -speed) was calculated for each interval (see Figure 1). The driving directions were not distinguished because the characteristics of the road design are the same for all the included midblocks. Each interval is evaluated independently from the adjacent intervals.

Linear regression analysis was used to model the connection between speed and interval. Furthermore, we used LOESS, a data-driven nonparametric estimate of the relationship between variables in windows of the data - windows that are shifted along the axes in the data set in order to draw a best fitting curve (Cleveland, 1979). The LOESS was estimated to identify a basic model of the relationship between the speed and interval in the data set. In the univariate analyses, more variables were included in the basic model mentioned above. The final model comprised the variables that were significant at the $5 \%$ level (in the univariate analyses) that were also statistically significant in a multivariate model that evaluated the simultaneous effects of the included variables on speed. Robust standard errors were estimated. When developing the model, it was found that it was difficult to model information on road width and distance from the roadside 
to the buildings in actual numbers. Therefore, the values for these two variables were classified in tertiles, which allowed us to build a better model.

\section{RESULTS}

Before calculating the 85-speed between the pairs of speed humps (intervals), we removed one outlier with a maximum speed above $200 \mathrm{~km} / \mathrm{h}$. We began with a data set of 378 intervals (and 570 speed humps); however, before conducting the analysis, we removed observations with intervals above $400 \mathrm{~m}(n=8)$ because there were not enough of them to contribute meaningfully to the analyses. We also removed 12 intervals because they were based on less than 25 observations or less than 10 individual drivers. After these exclusions, we ended up with a data set of 358 intervals, which originated from a total of 694,815 passages. The mean (standard deviation [SD]) 85-speed was $57.3 \mathrm{~km} / \mathrm{h}(5.4 \mathrm{~km} / \mathrm{h})$ with a minimum of $39.5 \mathrm{~km} / \mathrm{h}$ and a maximum of $70.3 \mathrm{~km} / \mathrm{h}$. Thus, in most of the intervals ( $91 \%)$, the 85 -speed was above the speed limit of $50 \mathrm{~km} / \mathrm{h}$. The mean length of the intervals (SD) was $181.2 \mathrm{~m}(59.8 \mathrm{~m})$ with a minimum length of $27 \mathrm{~m}$ and a maximum length of $385 \mathrm{~m}$. Additional characteristics of each interval were measured (Table 1). Most of the intervals stemmed from through roads (57 \%); $36 \%$ of the intervals originated from main roads. Relatively few intervals $(7 \%)$ stemmed from residential roads. The variables of road width and distance to buildings were divided into three categories with midpoints at the $33^{\text {rd }}$ percentile and the $67^{\text {th }}$ percentile, respectively. As was expected with the studied road types, most of the intervals (83\%) had a pedestrian area, whereas half of the intervals had either a bicycle path or a bicycle lane.

As a first step, we considered the relationship between the 85-speed and the interval in the data set for all 358 intervals. To obtain an idea of the form of the association, we drew a LOESS curve (see Figure 2). The fitted curve in the plot was estimated in the linear regression analysis (further description below). When evaluated by eye, we noticed a strong similarity among the curves.

The LOESS curve suggested a logarithm transformation of both the speed and the interval $\left(\mathrm{R}^{2}=0.27\right)$; in order to increase the R-square measure, we also included the untransformed interval in a basic model of the functional relationship between the speed and the interval between the speed humps $\left(\mathrm{R}^{2}=0.28\right.$ was slightly better). A $p$-value of 0.0003 for the untransformed interval indicated that this variable was necessary for a better fit. The model estimates are presented in Table 2 (basic model in the left column). This study confirmed a clear positive correlation between the maximum speeds between the speed humps and the interval between each pair of speed humps. The speed increases rapidly based on the interval size until approximately $200 \mathrm{~m}$, then the speed levels off, ending at a maximum of approximately $60 \mathrm{~km} / \mathrm{h}$. After the fitting of the basic model, we included additional interval characteristics in a model selection process.
Registration of one trip on one interval

The highest speed is selected

All selected speeds at one interval are collected

The 85 percentile of all maximum speeds is selected

This is used as the value for this interval

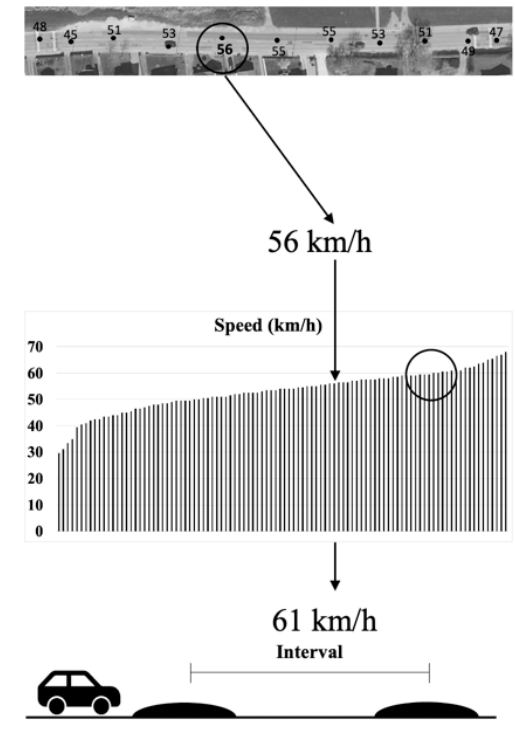


Table 1. Descriptive statistics of the speed-interval data and related factors measured in the individual assessment of each speed hump.

\begin{tabular}{lccccc}
\hline Variable & $\boldsymbol{n}$ & Mean or $\%$ & SD & Min. & Max. \\
\hline 85 -speed $(\mathrm{km} / \mathrm{t})$ & 358 & 57.27 & 5.44 & 39.46 & 70.24 \\
\hline Interval $(\mathrm{m})$ & 358 & 181.25 & 59.81 & & \\
\hline Road type & 25 & & & & \\
Residential roads & 129 & $36 \%$ & & \\
Main roads & 204 & $57 \%$ & & \\
Through roads & & & & \\
\hline Road width & 119 & $33 \%$ & & \\
$3.6-6 \mathrm{~m}$ & 119 & $33 \%$ & & \\
$6.1-6.8 \mathrm{~m}$ & 120 & $33 \%$ & & \\
$6.9-11 \mathrm{~m}$ & & & & \\
\hline Distance to buildings & 119 & $33 \%$ & & \\
$5.8-11.9 \mathrm{~m}$ & 119 & $33 \%$ & & \\
$12.0-16.0 \mathrm{~m}$ & 120 & $33 \%$ & & \\
$16.1-66.3 \mathrm{~m}$ & & & & \\
\hline Pedestrian area & 296 & $83 \%$ & & \\
Yes & 62 & $17 \%$ & & \\
No & & & & \\
\hline Bicycle path & 86 & $76 \%$ & & \\
Yes & 272 & & & \\
No & 95 & & & \\
\hline Bicycle lane & 263 & & & \\
Yes & & & & \\
No & & & & \\
\hline
\end{tabular}

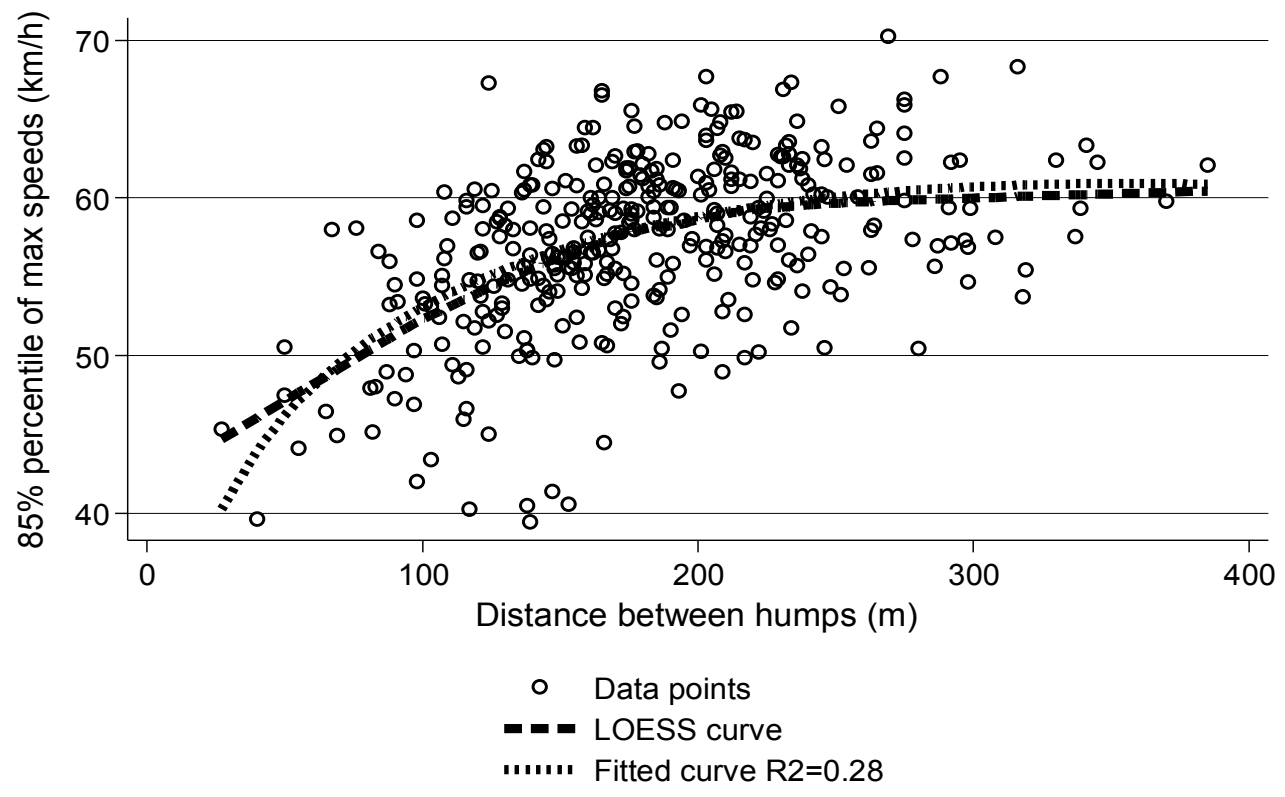

Figure 2. The distribution of the 85-speed by intervals between the speed humps in 358 different pairs of consecutive humps. The LOESS curve is a data-generated estimate of the correlation between the speed and the interval; the dotted curve depicts the curve estimated in the linear regression analysis. The plot was created as an aid in the modelling process. 
Table 2. Three models of the relation between the logarithm of the 85-speed between the speed humps in each of the 358 intervals and various characteristics of the intervals were estimated in the model selection process. Information in the left column is from the basic model that was estimated to describe the base relation between the speed and interval. Information in the middle column is from the full model in which all the variables from Table 1 were added to the basic model. Information in the right column is from the final model, where all the nonsignificant variables at the $5 \%$ level were discarded from the full model. (See text for details regarding the model selection process.)

\begin{tabular}{|c|c|c|c|c|c|c|c|c|c|}
\hline \multirow[t]{2}{*}{ Variable } & \multicolumn{3}{|c|}{ Basic model } & \multicolumn{3}{|c|}{ Full model } & \multicolumn{3}{|c|}{ Final model } \\
\hline & Estimate & Robust SE & $p$ & Estimate & Robust SE & $p$ & Estimate & Robust SE & $P$ \\
\hline Ln (Interval) & 0.248 & 0.048 & $<0.001$ & 0.222 & 0.036 & $<0.001$ & 0.216 & 0.038 & $<0.001$ \\
\hline Interval & -0.0007 & 0.0003 & 0.015 & -0.0007 & 0.0002 & 0.003 & -0.0006 & 0.0002 & 0.007 \\
\hline \multicolumn{10}{|l|}{ Road type } \\
\hline $\begin{array}{l}\text { Residential } \\
\text { roads (ref) }\end{array}$ & & & & 0 & & & 0 & & \\
\hline Main roads & & & & 0.125 & 0.019 & $<0.001$ & 0.129 & 0.018 & $<0.001$ \\
\hline Through roads & & & & 0.165 & 0.02 & $<0.001$ & 0.179 & 0.018 & $<0.001$ \\
\hline \multicolumn{10}{|l|}{ Road width } \\
\hline $3.6-6 \mathrm{~m}$ (ref) & & & & 0 & & & & & \\
\hline $6.1-6.8 \mathrm{~m}$ & & & & 0.003 & 0.009 & 0.73 & & & \\
\hline $6.9-11 \mathrm{~m}$ & & & & -0.012 & 0.1 & 0.232 & & & \\
\hline \multicolumn{10}{|l|}{$\begin{array}{l}\text { Distance to } \\
\text { buildings }\end{array}$} \\
\hline $5.8-11.9 \mathrm{~m}$ (ref) & & & & 0 & & & 0 & & \\
\hline $12.0-16.0 \mathrm{~m}$ & & & & 0.032 & 0.009 & $<0.001$ & 0.042 & 0.008 & $<0.001$ \\
\hline $16.1-66.3 \mathrm{~m}$ & & & & 0.045 & 0.009 & $<0.001$ & & & \\
\hline Pedestrian area & & & & -0.016 & 0.01 & 0.119 & & & \\
\hline Bicycle path & & & & 0.004 & 0.01 & 0.712 & & & \\
\hline Bicycle lane & & & & 0.018 & 0.009 & 0.056 & & & \\
\hline Intercept & 2.891 & 0.2 & $<0.001$ & 2.864 & 0.147 & $<0.001$ & 2.867 & 0.159 & $<0.001$ \\
\hline $\mathrm{R}^{2}$ & 0.28 & & & 0.59 & & & 0.57 & & \\
\hline
\end{tabular}

The model selection process continued through the univariate analysis of each of the categorical variables (shown in Table 1) in the basic model comprising the logarithm of the interval variable and the untransformed interval variable. All the variables were statistically significant at the $5 \%$ level. We then created a multivariate regression model of the logarithm of the 85-speeds at each interval in the logarithm of interval, interval and the categorical variables. We then, again, eliminated the variables that were statistically insignificant at the $5 \%$ level and ended up with a model comprising the logarithm of the interval variable, the interval variable, road type and distance to buildings. We tested whether the two categories, "12.0-16.0 m" and "16.1-66.3 m", could be pooled, which was possible ( $p=0.11)$; thus, we end up with a final model as displayed in the column to the right in Table 2. As seen, the estimates are very similar from model to model, which may indicate that the simplification did not have a significant effect on the results.

The final model is depicted in the graphs presented in Figures 3-5 for each of the road types: main roads, through roads and residential roads. 


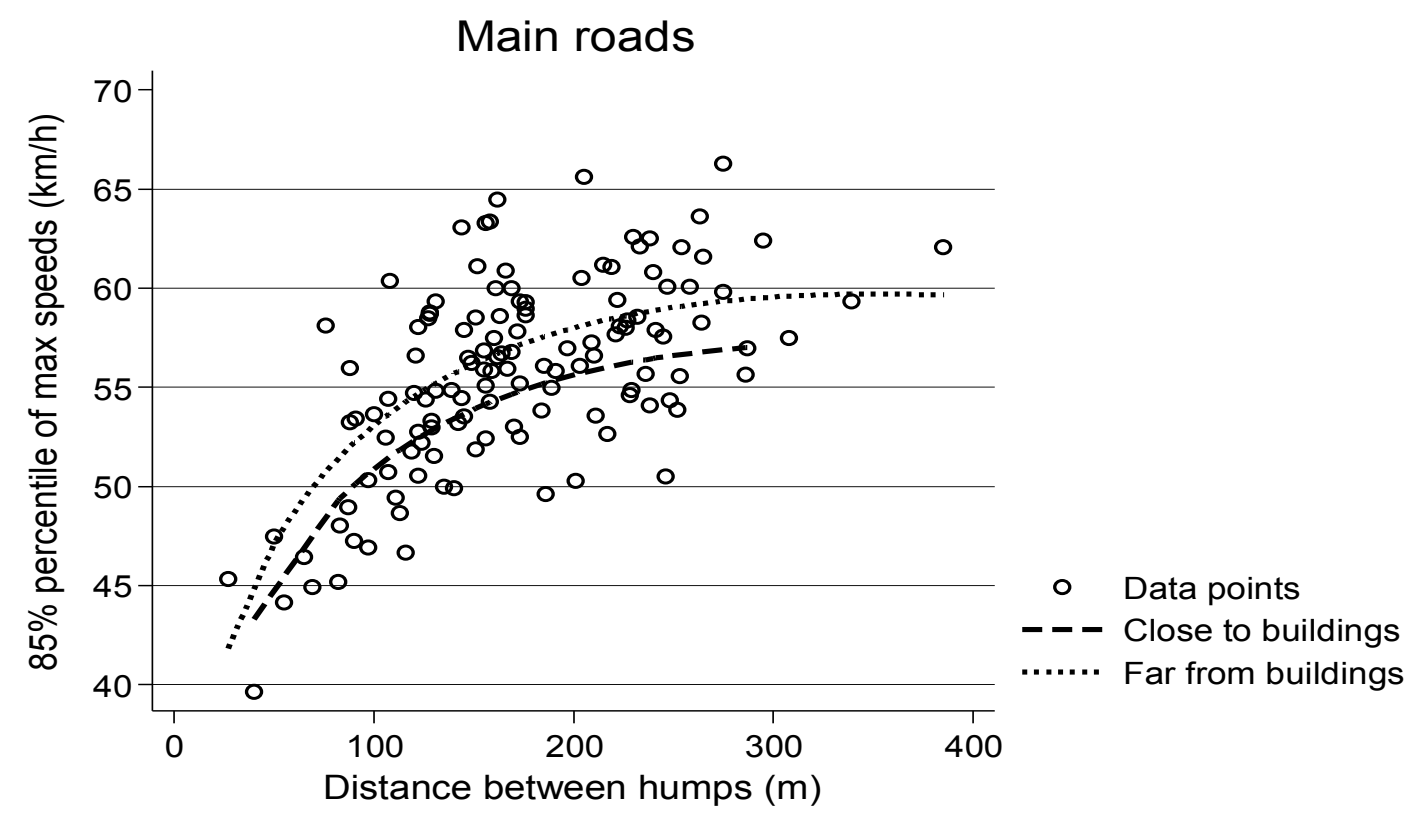

Figure 3. The speeds on the main roads as a result of the intervals between the speed humps and the roadside buildings.

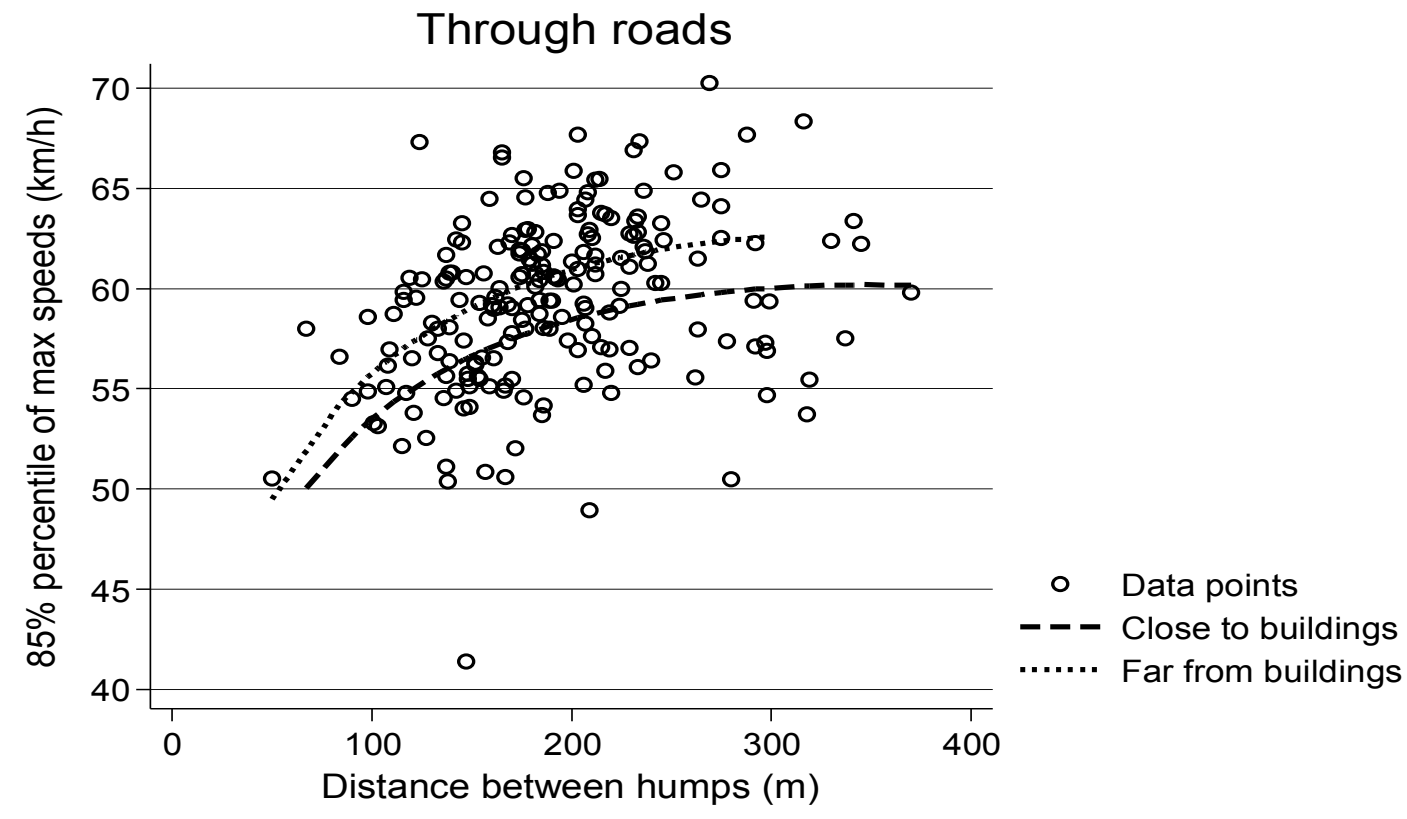

Figure 4. The speeds on the through roads as a result of the intervals between the speed humps and the roadside buildings. 


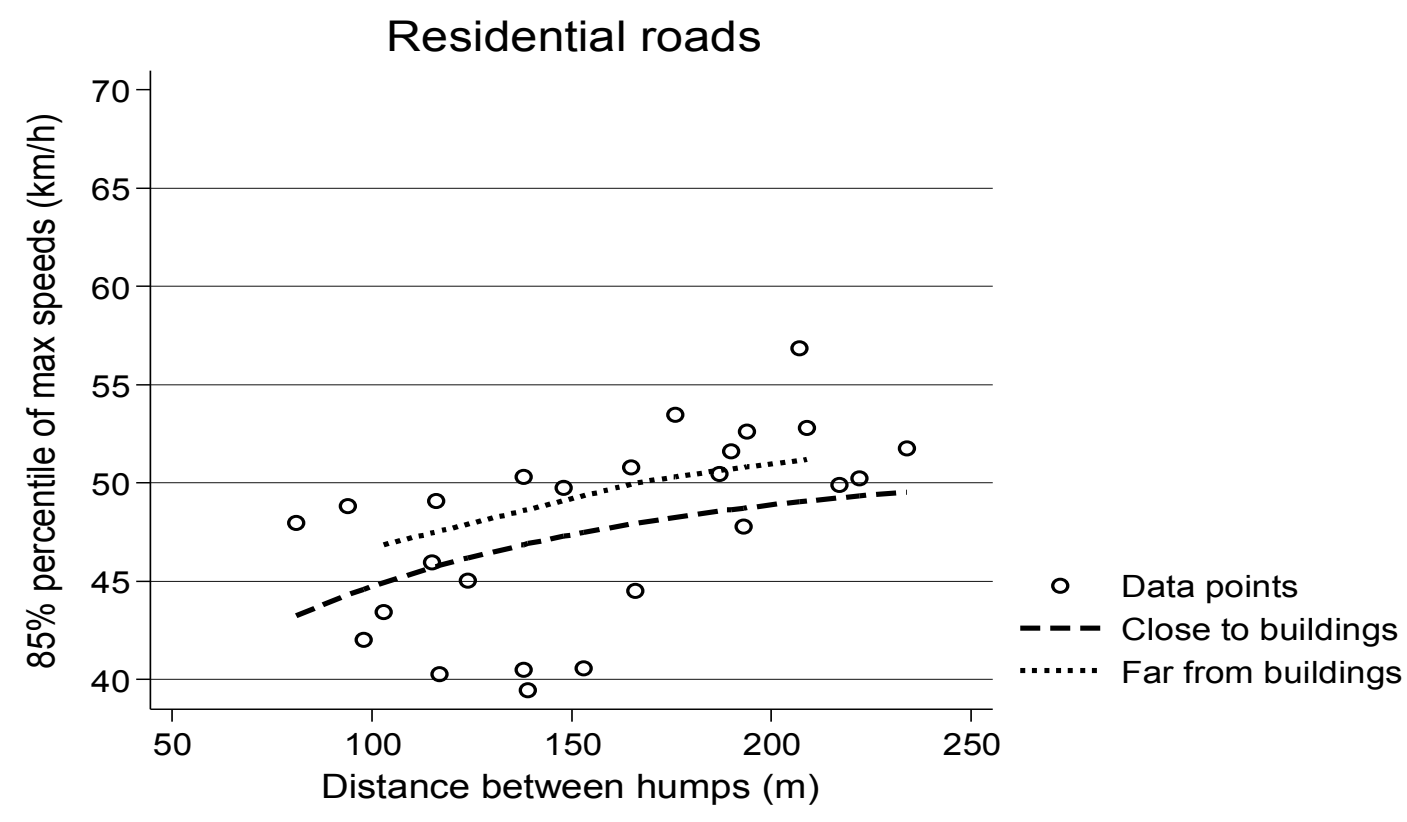

Figure 5. The speeds on the residential roads as a result of the intervals between the speed humps and the roadside buildings.

Regardless of the intervals between the speed humps, in general, the 85-speed is lower on the residential roads in comparison to the main roads and the through roads ( $p<0.001$ for both). Moreover, a speed difference was found between the main roads and the through roads $(p<0.001)$ with the highest speeds on the through roads. Additionally, the distance to the roadside buildings is essential for the 85 -speed. The longest estimated interval on the main roads, if speeding should be avoided, was $70 \mathrm{~m}$ and $89 \mathrm{~m}$ away from the SC and close to the buildings, respectively. Similar results were found for the through road (52 $\mathrm{m}$ and $67 \mathrm{~m}$, respectively) and for the residential roads (164 $\mathrm{m}$ and $261 \mathrm{~m}$, respectively).

Considering the information presented in Table 2, Equation (1) can be used to depict the relationship between the speed, interval, road type and distance to the roadside buildings.

(1)

$$
\begin{gathered}
85-\text { speed }=17,58 \cdot \text { interval } l^{0,216} \cdot e^{-0,0006 \cdot \text { interval }} \cdot\left\{\begin{array}{c}
1 \text { if residential road } \\
1,137 \text { if main road } \\
1,195 \text { if through road }
\end{array}\right. \\
+\left\{\begin{array}{c}
1 \text { if buildings } \leq 11,9 \mathrm{~m} \text { away } \\
1.043 \text { if buildings }>11,9 \text { m away }
\end{array}\right.
\end{gathered}
$$

The model shows that the interval between the speed humps, the road type and whether or not the buildings are close to the roadside affect the driving speed. All things being equal, this results in increased intervals and in increased speed although the effect is $23 \%$ higher with an interval of $50 \mathrm{~m}$ in comparison to an interval of $200 \mathrm{~m}$. Moreover, in comparison to the residential roads, the 85 -speed was $14 \%$ and $20 \%$ higher on the main roads and the through roads, respectively. If the roadside buildings are distant, cf. the definition, the speed is $4 \%$ higher.

\section{DISCUSSION}

\subsection{Methods}

FCD are very numerous, and successful driving behaviour analyses based on that data set require a proper simplification of the data in order to see the pattern of relevance and to extract tangible results. This is especially crucial because each passage can be represented with hundreds of observations. If, for example, the speed profiles for each interval were used as they are in Agerholm et al. (2017) and Jørgensen et al. (2013), a full representation of FCD would appear, and it would be possible to obtain clear results concerning each interval depending on the distance of the interval to the speed hump. While the mean speed and 85 -speed could be shown, it would be dif- 
ficult to group the intervals because all the variables would have to be identical in order to group them. Thus, there would have been a range of models that have little or no connection with each other.

Hence, in order to model FCD across the intervals, it is necessary to identify one observation per passage per interval. We have chosen to use the highest registered speed per passage in order to clarify the extent of the speeding that occurs in these intervals. The use of the mean speed or the 85-speed ( $85^{\text {th }}$ percentile of the individual passages) would even-out any speeding in the interval. Moreover, in opposition to the maximum speed, it can be considered that the mean speed and the 85 -speed of the passages of intervals are affected by the interval between the speed humps (Figure 6). The mean speed for the entire interval, regardless of any reduced speed near the speed humps, will underestimate any speeding problems in each interval because the mean speed is often lower than the speed limit due to the reduction in speeds close to the SC measures. Additionally, it would have treated the shorter interval results differently from the longer interval results, as the share of driving under the influence of the speed hump would have been greater.

Based on the aggregated results used here, one could argue that we should have chosen the maximum or mean speed instead of the 85-speed; however, in order to avoid dilution of any speeding problems on this aggregate level, the mean speed is not suitable. Moreover, the maximum speed is reasonably not appropriate, as it would reflect any individual extreme driving behaviour, exaggerate any speeding problems, and is not based on the traditional approach used to measure any speeding problems via a chosen percentile.

A clear advantage of the study is the relatively large data set consisting of measurements from a total of 358 intervals. Therefore, it is surprising that no further variables became statistically significant in the multivariate analysis. We concluded that the effect of the size of the interval and the distance to the buildings were predictors of the 85 -speed that were so strong that they would, somehow, eliminate the importance of other factors. As seen in Table 2, we found a marginally statistically significant effect of a bicycle lane $(p=0.06)$. This might be due to the fact that car drivers can experience bicycle lanes as being well-defined, so they can relax and drive a bit faster. However, due to its low contribution and its marginally statically significant effect, we have decided to skip it in the final model.

\subsection{Results and general effects}

SCs on main or through roads could be disputable and, in general, they are not used. However, the present study, as well as the majority of the studies discussed earlier in this paper, show that SCs are necessary if a suitable speed must be met. However,

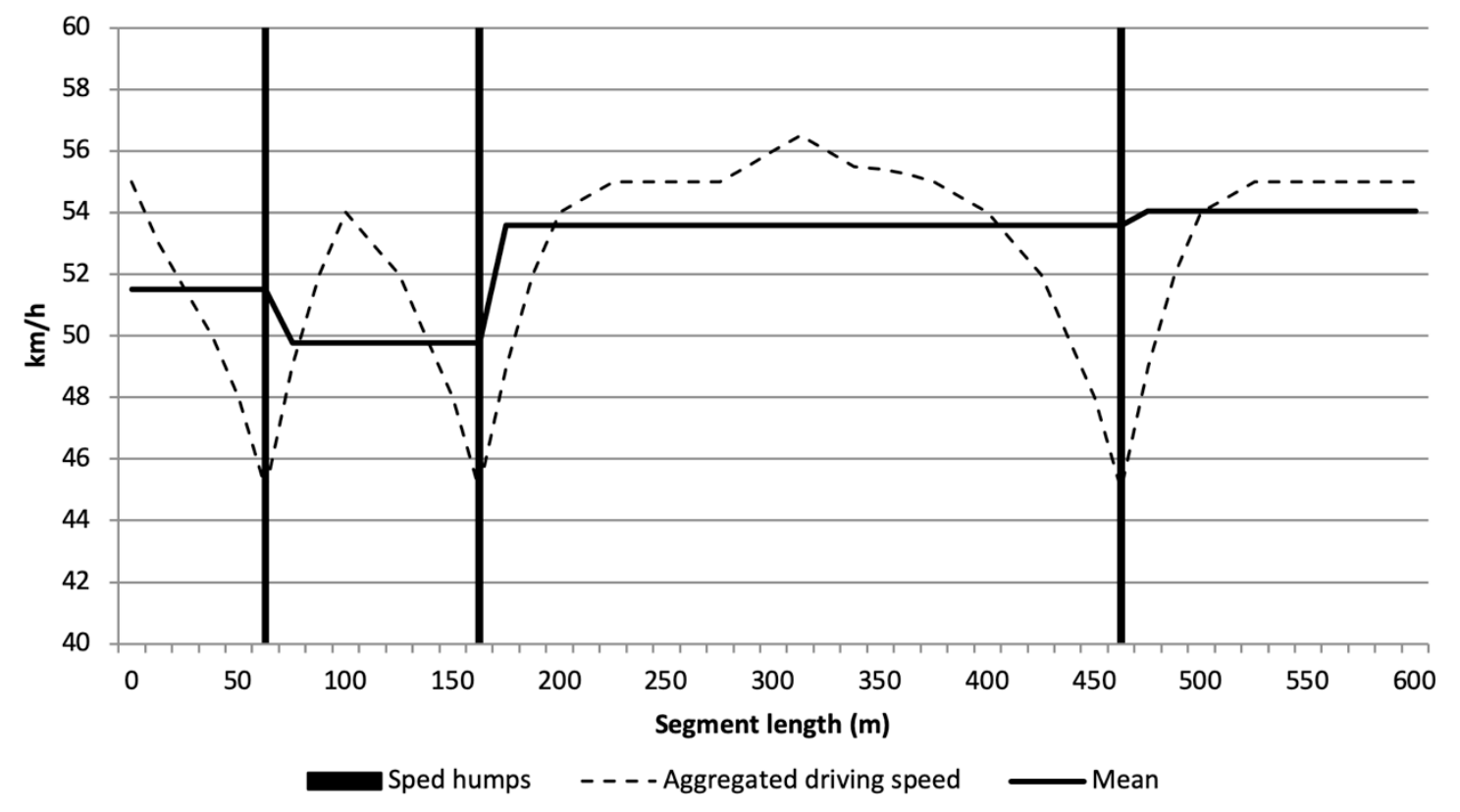

Figure 6. Principal sketch with the connection between the mean speed and the interval between the speed humps. 
this requirement has to be balanced with the environmental costs of any speed variation, extra abrasion or discomfort among especially professional drivers in combination with any extra time use when the choice of speed limit must be made. Therefore, implementing SCs on main or through roads represents a tradeoff between safety and other factors.

In the present study, we focused on roads with a $50 \mathrm{~km} / \mathrm{h}$ speed limit because that is the main speed limit in urban areas in Denmark. Other studies, such as Rosén, Stigson and Sander (2011), Elvik, (2013) and the Swedish Vision Zero, have reported that, from a safety perspective, a speed limit of $30 \mathrm{~km} / \mathrm{h}$ is suitable in built-up areas, where a significant number of vulnerable road users are expected to be present. However, other perspectives affect the choice of speed limits; of these, travel time is important, especially on main and through roads. It is due to time-cost understanding, but also in order to keep these roads as the main access route for most road users instead of driving on small, narrow streets in built-up areas, which might be slightly shorter, but much riskier from the vulnerable road users' perspective. Because the resources for establishing SCs are limited and it is difficult to keep the driving speed low without physical interventions, at least in Denmark, the road authorities, in cooperation with the police, have been hesitant to require speed limits of $30 \mathrm{~km} / \mathrm{h}$ or $40 \mathrm{~km} / \mathrm{h}$ without SCs or a road design, which makes it obvious that a low speed limit is the best option.

From a safety perspective, however, the perfect strategy would be to designate a $30 \mathrm{~km} / \mathrm{h}$ speed limit for all residential roads and matching SCs. On the roads in built-up areas that are meant for general traffic flows where it is not possible to separate motorised traffic from vulnerable road users, a $50 \mathrm{~km} / \mathrm{h}$ speed limit is recommended, but again with the matching SCs. A higher speed limit would only be suitable on main or through roads with none or very few vulnerable road users and limited access to/from roadsides.

\section{SUMMARY AND CONCLUSION}

In general, speeding is a problem in most road networks. This is especially true in the case of built-up areas, where road design, although in combination with speed limits and enforcement in many cases, does not designate an obvious suitable speed. In many countries, speed humps are used as an SC measure in built-up areas. The design of the speed humps and their mutual intervals affect the SC effect from them. While many studies have shown a clear SC effect, the maximum recommendable interval between the speed humps has been found to be lower than what is typically implemented. Moreover, it has been reported that the interval between the speed humps is not the only factor that affects the speed choice among car drivers. In Denmark, where speed humps with a height of $0.1 \mathrm{~m}$ and a length of $9.5 \mathrm{~m}$ are widely used, their SC effect has been evaluated in this large-scale study concerning roads with a $50 \mathrm{~km} / \mathrm{h}$ speed limit. In total, the speeds in 358 intervals between speed humps were studied based on the highest measured speed from each passage. It was found that the 85 -speed was $57.3 \mathrm{~km} / \mathrm{h}$, and the studied intervals were divided into three road types: main roads, through roads and residential roads.

The study showed that the 85 -speed increased by the interval length up to approximately $200 \mathrm{~m}$. The 85 -speed levelled out at around $60 \mathrm{~km} / \mathrm{h}$ from intervals above a length of $200 \mathrm{~m}$. The type of road had an impact on the 85-speed, with the lowest speed on the residential roads and the highest speed on the through roads. Also, the distance from the roadside buildings to the roadside modified the association between 85 -speed and interval length as the speed increased by distance to the roadside buildings. Our model suggests that the maximum length of interval between speed humps on the three road types with relatively large distance to the roadside buildings is $52 \mathrm{~m}, 70 \mathrm{~m}$ and $164 \mathrm{~m}$ for through roads, main roads, and residential roads respectively. Where the buildings are relatively close to the roadside, the maximum lengths of intervals are recommended to be $67 \mathrm{~m}, 89 \mathrm{~m}$ and $261 \mathrm{~m}$ for through roads, main roads and residential roads, respectively.

The effect from the speed humps was approximately $23 \%$ higher with an interval of $50 \mathrm{~m}$ in comparison to an interval of $200 \mathrm{~m}$. In areas in which the buildings were situated farther from the roadside, the speeds were $4 \%$ higher. Overall, speed humps are an efficient way to reduce speeding in built-up areas, but the individual speed humps must be placed at an interval that is significantly shorter than the recommended interval to avoid speeding. This is especially the case where roadside buildings are situated farther from the road, and it does not seem to be interpreted as an urban area by the drivers. 
Acknowledgement: We would like to thank the Danish Innovation Fund via the DiCyPS Center for its support in the data extraction and analyses. We also owe many thanks to the staff members behind the ITS Platform, the European Regional Development Fund and the North Denmark Region for their assistance in the data collection.

\section{REFERENCES}

Agerholm, N. (2011) Speed regulating Effects of Incentive-based Intelligent Speed Adaptation in the short and medium term. Aalborg University.

Agerholm, N. et al. (2014) Full-Automatic Parking registration and payment: In principle GNSS-based road pricing. 10th ITS European Congress, Helsinki, Finland 16-19 June 2014, Helsinki: ERTICO - ITS Europe, 1-9.

Agerholm, N., Knudsen, D. and Variyeswaran, K. (2017) Speedcalming measures and their effect on driving speed - Test of a new technique measuring speeds based on GNSS data, Transportation Research Part F: Traffic Psychology and Behaviour, 46, 263-270. doi: 10.1016/j.trf.2016.06.022.

Ambros, J., Novák, J., Neuwirth, P., Kieć, M., Dudek, D., Andriejauskas, T. (2017) Using speed profiles to investigate the impact of traffic calming measures, 29th International Baltic Road Conference, Tallinn, 1-6.

Antic, B., Pesic, D., Vujanic, M., \& Lipovac, K. (2013) The influence of speed bumps heights to the decrease of the vehicle speed - Belgrade experience, Safety Science, 57, 303-312.

Danish Road Directorate (2013) Håndbog - Fartdcempere, Anlag og Planlagning (Manual - Speed Calming Measures, Facilitation and Planning. Denmark.

Cleveland, W. S. (1979). Robust locally weighted regression and smoothing scatterplots. Journal of the American Statistical Association, 74, 829-836.

Eksler, V., Popolizio, M., \& Allsop, R. (2009) How far from Zero? - Benchmarking of road safety performance in the Nordic countries. Brussels.

Elvik, R. (2001) Area-wide urban traffic calming schemes: a meta-analysis of safety effects, Accident Analysis and Prevention, 33(3), 327-336.

Elvik, R. et al. (2009) The Handbook of Road Safety Measures: Second Edition, Oslo: Emerald Group Publishing Limited.

Elvik, R. (2013) A re-parameterisation of the Power Model of the relationship between the speed of traffic and the number of accidents and accident victims, Accident Analysis and Prevention. 50, 854-860. doi: 10.1016/j.aap.2012.07.012.

Gitelman, V. et al. (2016) Changes in road-user behaviors following the installation of raised pedestrian crosswalks combined with preceding speed humps, on urban arterials, Transportation Research Part F-Traffic Psychology and Behaviour, 46, 356-372.
Gøeg, P. R. et al. (no date) Effects of GDPR applied to FCD, in, 14th ITS European Congress, Lisbon, 1-10.

Hauer, E. (1997) Observational before-after studies in road safety - Estimating the effect of highway and traffic engineering measures on road safety. Toronto: Emerald Group Publishing Limited.

Jørgensen, M. et al. (2013) Driving speed on thoroughfares in minor towns in Denmark, 26th ICTCT Workshop, 1-10.

Karlgren, J. (2005). Bilisters hastighetsval i relation till gaturummets utformning och händelser (Drivers' speed choice in connection with the street design and incidents). Gothenburg.

Lahrmann, H. et al. (2012) ITS Platform North Denmark: idea, content, and status, 19th ITS World Congress, 1-12.

Lahrmann, H. et al. (2013) The development of an open platform to test ITS solutions, in 9th ITS European Congress, Dublin, 1-5.

Nilsson, G. (2004) Traffic safety dimensions and the Power Model to describe the effect of speed on safety, Lund: Lund Institute of Technology and Society, Traffic Engineering. Retrieved from: https://lup.lub.lu.se/search/publication/b0b1da1a-19714524-8f51-3909c8cf8d43.

Rosbach, O. (1996) Miljoprioriterede gennemfarter - Effekter i 21 byer - Rapport 70 (Environmentally prioritised thoroughfares - effects in 21 towns).

Rosén, E., Stigson, H., \& Sander, U. (2011) Literature review of pedestrian fatality risk as a function of car impact speed, Accident Analysis and Prevention, 43(1), 25-33.

Várhelyi, A. (1996) Dynamic speed adaptation based on information technology: a theoretical background. Bulletin 142.

Wellis, W. et al. (2004) 21 miljøprioriterede bygennemfarter Den trafiksikkerhedsmassige effekt (21 Environmentally prioritised thoroughfares - the traffic safety effect). 